\section{Nerve trimming device}

One of the prerequisites for an appropriate nerve repair in case of peripheral nerve injury is to have well prepared and viable cut ends of the nerve to be repaired. The conventional method ${ }^{[1]}$ of holding the cut ends of the nerve with forceps and using an 11 number blade or a micro scissors supporting the nerve with the spatula covered with a moist gauge, have objections and needs relook. Equipment like Laser and Nerve Miter box ${ }^{[2]}$ are expensive and are not readily available.

We the authors are describing a simple and effective way of atraumatically trimming the lacerated nerves before repair.

The nerve trimming device that is being described in this original work is very simple in its design which

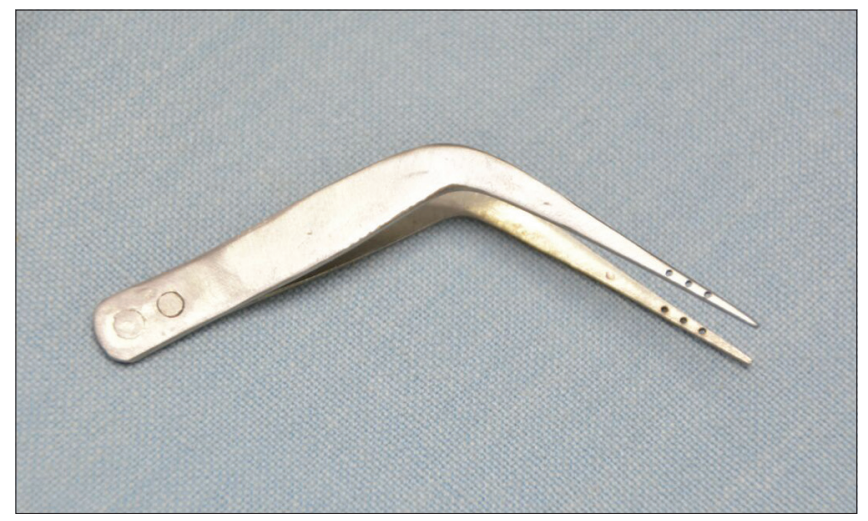

Figure 1: Nerve trimming device consists of a curved (70 degree) smooth forceps with a tapered long and narrow tip made up of stainless steel. It consist of $4 \mathrm{cms}$ long forceps with a tapered smooth end of $1 \mathrm{~mm}$. The prongs of the forceps themselves are proximally curved at an angle of 70 degrees to be used as a handle. This curved handle is sufficiently long enough (4 cms) for the ease of handling [Figure 1]. At a sufficient distance from the tip of the forceps, there are 3 co-linear perforations (big enough to accept 23/25 gauge needles) on both the shafts of the prongs of the forceps allowing the surgeon to transfix the full thickness of the structure which is to be trimmed (including both the anterior and the posterior walls). Depending on the size of the structure to be trimmed one or two needles can be used for the same purpose. This provides the surgeon a reasonable control over the structure to be trimmed in all planes with a gentle " vice" like grip which is fully adjustable by his nondominant hand while trimming. A gentle longitudinal

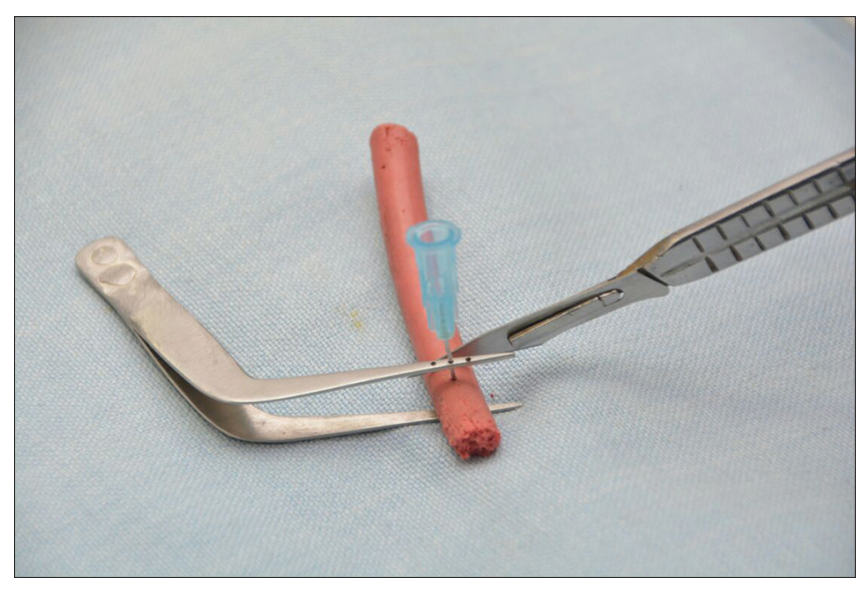

Figure 2: Simulation of nerve assembled on the device ready for trimming 


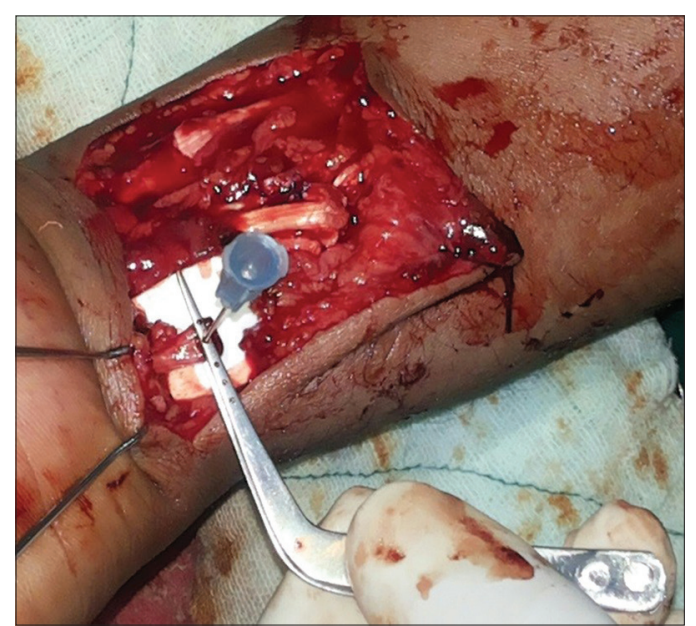

Figure 3: Intra-operative demonstration of the nerve trimmer assembly

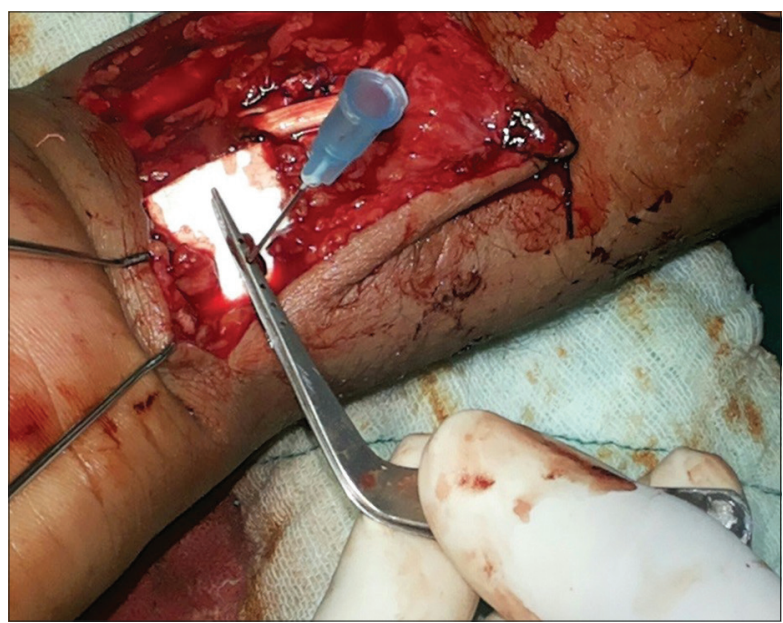

Figure 4: Damaged nerve resected along with the trimmer

traction will provide both anterio -posterior and medio -lateral stability allowing the surgeon to transect the nerve with the blade guided by the jig like effect and support provided by the prongs of the frame as shown in Figures 2-4. Patent of the forceps is pending.

\section{Financial support and sponsorship}

Nil.

\section{Conflicts of interest}

There are no conflicts of interest.

Jagannath Bantwal Kamath, Mithun Pai,
Premjit Rabindra Sujir
Department of Orthopaedics,
Kasturba Medical College, Mangalore,
Karnataka, India
Address for correspondence:
Dr. Premjit Rabindra Sujir,
Kasturba Medical College, Mangalore,
Karnataka, India.
E-mail: premjit78@gmail.com

\section{REFERENCES}

1. Kline DG, Hudson AR. Nerve Injuries: Operative Results for Major Nerve Injuries, Entrapments, and Tumors. $1^{\text {st }}$ ed. Philadelphia, PA: WB Saunders Company; 1995;Ch6-10.117-289.

2. Field JH. Peripheral nerve suturing using a nerve miter box to trim the ends. Plast Reconstr Surg 1969;44:605-7.

This is an open access journal, and articles are distributed under the terms of the Creative Commons Attribution-NonCommercial-ShareAlike 4.0 License, which allows others to remix, tweak, and build upon the work non-commercially, as long as appropriate credit is given and the new creations are licensed under the identical terms.

\begin{tabular}{|l|l|}
\hline \multicolumn{2}{|c|}{ Access this article online } \\
\hline Quick Response Code: & Website: \\
\hline
\end{tabular}

How to cite this article: Kamath JB, Pai M, Sujir PR. Nerve trimming device. Indian J Plast Surg 2018;51:343-4.

(C) 2019 Indian Journal of Plastic Surgery | Published by Wolters Kluwer - Medknow 